\title{
Direct Osmosis for Reverse Osmosis Fouling Control: Principles, Applica- tions and Recent Developments
}

\author{
Jian-Jun Qin*, ${ }^{1}$, Boris Liberman ${ }^{2}$ and Kiran A. Kekre ${ }^{1}$ \\ ${ }^{I}$ The Centre for Advanced Water Technology, PUB Consultants Pte Ltd; ${ }^{2} I D E$ Technologies Ltd, Israel
}

\begin{abstract}
Reverse osmosis (RO) has been widely applied in various water and wastewater treatment processes as a promising membrane technology. However, RO membrane fouling is a global issue, which limits it operating flux, decreases water production, increases power consumption and requires periodical membranes Cleaning-in-Place (CIP) procedure. This may result in low effectiveness, high cost and adds environmental issues related to the CIP solutions disposal. Forward osmosis (FO) or direct osmosis (DO) is the transport of water across a semi-permeable membrane from higher water chemical potential side to lower water chemical potential side, which phenomenon was observed in 1748 . The engineered applications of FO/DO in membrane separation processes have been developed in food processing, wastewater treatment and seawater/brackish water desalination. In recent years, DO has been increasingly attractive for RO fouling control as it is highly efficient and environmentally friendly technique which is a new backwash technique via interval DO by intermittent injection of the high salinity solution without stoppage of high pressure pump or interruption of the operational process and allows keeping RO membrane continuously clean even in heavy bio-fouling conditions and operating RO membranes at high flux. This paper provides the state-of-the-art of the physical principles and applications of DO for RO fouling control as well as its strengths and limitations.
\end{abstract}

Keywords: Backwash, direct osmosis, fouling control, reverse osmosis, salinity solution.

\section{INTRODUCTION}

Reverse osmosis (RO) is a pressure driven membrane process and has been widely applied in various water treatment processes as a promising technology. However, RO membrane fouling is a global issue, which limits it operating flux, decreases water production, increases power consumption and requires periodical membranes CIP procedure. This may result in low effectiveness, high cost and adds environmental issues related to the CIP solutions disposal. In past ten years, investigations on RO fouling and fouling control have been sharply increased as shown in Fig. (1), based on searching results from Engineering Village [1].

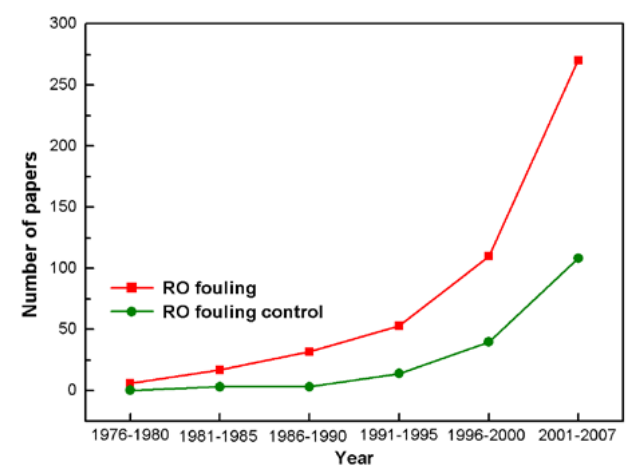

Fig. (1). Number of publications on RO fouling and its control vs. time.

*Address correspondence to this author at the Centre for Advanced Water Technology, PUB Consultants Pte Ltd, Israel; Tel: +65-63262914; Fax: +65-63262929; E-mail: jjqin@cawt.sui.com.sg
RO fouling is used to describe the potential deposition and accumulation of constituents in the feed stream on the RO membrane surface and it is usually classified into four major types: colloidal fouling organic fouling, inorganic fouling/scaling and biofouling. Better understanding the factors that will cause fouling is a fundamental for subsequent fouling control. Thus this topic has been focused in a great number of studies [2-7]. Three types of factors in general that have been explored in most studies are (1) chemical composition of feed water; (2) operating condition; (3) membrane properties, which are reviewed by Hong \& Elimelech [8]. Based on the factors affecting RO membrane fouling, various preventive strategies have been investigated and performed to reduce fouling. This generally includes pretreatment of the feed water (such as removing most flocculants by microfiltration (MF)/ultrafiltration (UF), adjusting $\mathrm{pH}$ and adding antiscalant), improvement of operating conditions (including the initial flux and flow velocity) and modification of membrane properties (like membrane hydrophilicity, surface roughness and charge via coating), and some other approaches. These typical preventive strategies and their effective results are described elsewhere [8].

Although all the above preventive strategies can slow the fouling rate to a certain extent, fouling is inevitable. Hence membrane cleaning is the long-term solution to remove foulants and maintain the membrane performance. It is usually conducted when there is a significant drop in flux and rejection of membranes or a need to increase operating pressure greatly. Cleaning methods include physical cleaning and chemical cleaning. Physical methods are based on mechanical forces to dislodge and remove foulants from the membrane surface such as forward/revise flushing and air sparging [9-11]. Foulants remaining after physical cleaning 
need to be removed by a chemical cleaning, depending on chemical reactions to weaken the cohesion forces between the membranes and foulants [12-14]. Of these methods, chemical cleaning is most widely used. However, it will cause low effectiveness of production due to the down time of frequent RO operation stoppage and high cost of cleaning agents, create environmental issues related to the waste chemical disposal and ultimately affect membrane life.

In recent years, development of FO/DO technology has been increasingly attractive for RO fouling control as it is highly efficient and environmentally friendly technique [1527] while the engineered applications of FO/DO in membrane separation processes have been reported for treatment and reclamation of wastewater [28-32], seawater/brackish water desalination [33, 34], pressure-retarded osmosis for generation of electricity [35, 36], food processing [37] and controlled drug release [38] that have been extensively reviewed by Cath et al. [39]. This paper will provide the stateof-the-art of the physical principles and applications of DO for RO fouling control as well as its strengths and limitations.

\section{PRINCIPLES OF DIRECT OSMOSIS FOR RO FOULING CONTROL}

Fig. (2) illustrates a comparison of the driving force in $\mathrm{DO}$ and RO processes. Osmosis or FO or DO is the natural transport of water across a semi-permeable membrane from higher water chemical potential side to lower water chemical potential side, i.e., passage of water is from the lower salt concentration side to the higher one because the lower the salt concentration, the higher the water chemical potential, which phenomenon was observed in 1748 . In practice, the osmotic pressure difference $(\Delta \Pi)$ between both sides of the semi-permeable membrane is used to describe the driving force for water transport although it does not need to apply a physical/hydraulic pressure on the membrane during DO process. The theoretical osmotic pressure $\Pi$ of a solution can be calculated using the Van't Hoff equation (1).
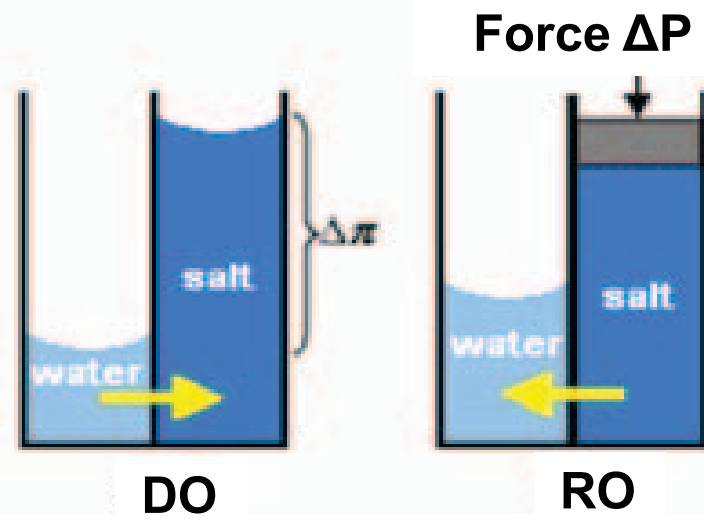

Fig. (2). Comparison of the driving force in DO and RO processes [39].

$$
\pi=n c \phi R T
$$

Where, $\mathrm{n}$ is the number of ions; $\mathrm{c}$ is salt concentration (M), $\phi$ is osmotic coefficient; $\mathrm{R}$ is the universal gas constant $\left(0.082057 \mathrm{~L} \cdot \mathrm{atm} \cdot \mathrm{K}^{-1} \cdot \mathrm{mol}^{-1}\right), \mathrm{T}$ is temperature $(\mathrm{K})$.
The water passage through the membrane is generally described and theoretically calculated by equation (2).

$J_{w}=A \cdot \sigma \cdot \Delta \pi$

Where $J_{w}$ is the water flux; $A$ is the water permeability constant of the membrane; $\sigma$ is the reflection coefficient; $\Delta \pi$ is the osmotic pressure differential [39].

In a RO process, on contrast, water driven under hydraulic pressure $(\Delta \mathrm{P})$ transfers through a semi-permeable $\mathrm{RO}$ membrane from the higher salt concentration side to the lower one and water flux can be calculated using equation (3).

$J_{w}=A(\Delta \mathrm{P}-\sigma \Delta \pi)$

The driving force of RO process is the pressure differential denoted in the following expression as well as illustrated in Fig. (3):

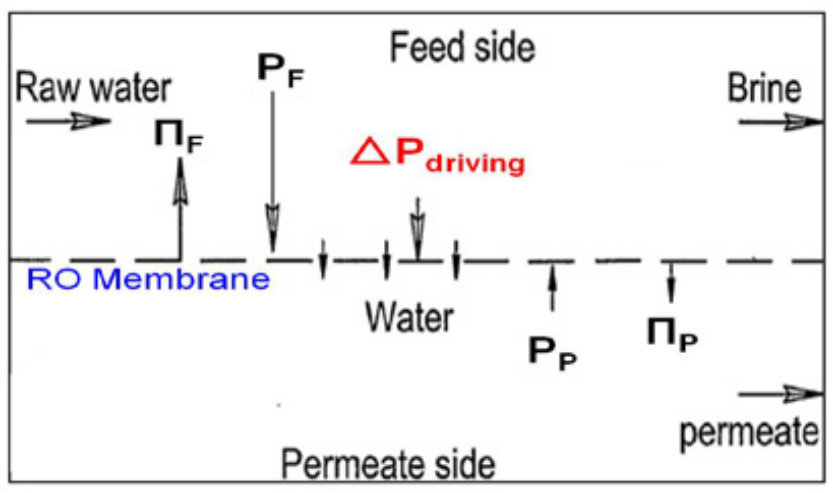

Fig. (3). Illustration of driving force in RO process.

$\Delta P_{\text {driving }}=\Delta P-\Delta \Pi=\left(P_{F}-P_{P}\right)-\left(\Pi_{F}-\Pi_{P}\right)$

Where, $\mathrm{P}_{\mathrm{F}}$ is the feed pressure; $\mathrm{P}_{\mathrm{P}}$ is the permeate pressure; $\Pi_{F}$ is the feed osmotic pressure; $\Pi_{P}$ is the permeate osmotic pressure. There are four forces to determine the driving force.

In a $\mathrm{RO}$ operation, the positive driving force drives water from the feed side to the permeate side.

$\Delta P_{\text {driving }}=\Delta P-\Delta \Pi=\left(P_{F}-P_{P}\right)-\left(\Pi_{F}-\Pi_{P}\right)>0$

When the backwash cleaning method is used to remove the foulants on the feed surface of RO membranes, a negative driving force is required to drive water from the permeate side to the feed side.

$\Delta P_{\text {driving }}=\Delta P-\Delta \Pi=\left(P_{F}-P_{P}\right)-\left(\Pi_{F}-\Pi_{P}\right)<0$

On one hand, this can be achieved by either reducing feed pressure or increasing permeate pressure. However, the former requires stoppage of the RO process, causes membrane sagging \& local elongation and limits the cleaning driving force to $\Pi_{\mathrm{F}}$ while the latter may cause damage to membranes, induce significant design change and limit the cleaning effect.

On the other hand, the negative driving force can be achieved by either decreasing $\Pi_{P}$ or increasing $\Pi_{F} \Pi_{P}$ can be neglected since the permeate osmotic pressure $\left(\Pi_{P}\right)$ is usu- 
ally very low compared to $\Pi_{F}$, whereas, high $\Pi_{F}$ can be easily gained by introduction of a high saline solution to the feed side. The higher $\Pi_{\mathrm{F}}$, higher driving force for backwash. Therefore, this method is called as DO cleaning/backwash since $\Pi_{\mathrm{F}}$ dominates the backwash process.

\section{FACTORS AFFECTING THE DO BACKWASH EFFICIENCY}

\section{Driving Force for DO Backwash}

Spiegler and Macleish [15] may be the pioneer to investigate DO backwash of RO (hyperfiltration) membranes. That time, knowledge on DO backwash under realistic hydraulic conditions was scarce although it was in practice known that periodic release of the brine pressure of a RO plant could temporarily recover production rate which had gradually reduced in the course of the plant operation. In their lab scale studies, an osmosis technique was developed to clean and possibly to decompact contaminated cellulose acetate RO membranes. 0.01-0.03 $\mathrm{M} \mathrm{NaCl}$ solution was used as the feed while deionized water was applied to flush at the permeate side. No trans-membrane pressure (TMP) or minimum TMP was maintained and net osmotic pressure was designed as the driving force during osmotic backwash. They found that the RO flux could be restored after DO backwash although the RO membranes were fouled with ferric hydroxide and performed significant flux decrease. However, it took at least 30 minutes for each operation of osmotic backwash.

The DO backwash method was later disclosed in the patents of JP2000-079328 and EP19960810678 [24]. In that method, when the membrane was cleaned, the RO production process was stopped, the saline solution was supplied to the feed side of the membrane essentially without pressure (or at least under pressure lower than the osmotic pressure of the solution), and no pressure was supplied at the permeate side as well. As a result, the permeate water was sucked back to the feed side essentially under the net osmotic pressure gradient. The treatment process might continue for at least 5 minutes.

Avraham et a l. [26] investigated the DO method under the sole influence of osmotic pressure gradient without application of external pressures at both feed and permeate sides. They considered the presence of concentration polarization (CP) layer on feed side during RO operation before DO backwash. Therefore, the net (effective) driving force for DO backwash was expressed as following equation:

$$
\begin{aligned}
& \Delta P_{\text {driving }}=\Delta P-\Delta \Pi_{\text {eff }}=-K_{C P}\left(\Pi_{F}-\Pi_{P}\right)(\Delta P=0), \\
& K_{C P}=\frac{C_{w}-C_{i w}}{C_{F}-C_{P}} \approx \frac{C_{w}-C_{P}}{C_{F}-C_{P}}
\end{aligned}
$$

Where $\mathrm{K}_{\mathrm{CP}}=\mathrm{CP}$ factor, $\mathrm{C}_{\mathrm{w}}=$ membrane wall concentration, $\mathrm{C}_{\mathrm{iw}}=$ internal membrane wall concentration, $\mathrm{C}_{\mathrm{F}}=$ feed concentration, and $C_{P}=$ permeate concentration [26].

In their study of DO backwash, internal concentration polarization was taken into account. At steady state the concentration gradient would form in the support layer of the membrane at the permeate side. When the feed concentration is low, the internal $\mathrm{CP}$ could be negligible, i.e., $\mathrm{C}_{\mathrm{iw}}=\mathrm{C}_{\mathrm{P}}$. However, when the feed concentration is high, the internal $\mathrm{CP}$ could play an important role and significantly affect membrane flux during the DO backwash.

Liberman [22] reported a new DO-HS technology for RO membrane cleaning, where a high salinity (HS) solution (which has high osmotic pressure) was injected into the feed water for a few seconds. Fig. (4) shows a schematic of RO and DO when a HS solution is injected.

In an actual RO system, a high pressure pump supplies the feed pressure $P_{F}$ to the membranes that is higher than $\Pi_{F}$. $\mathrm{P}_{\mathrm{F}}$ gradually decreases along the membrane (red line) while $\Pi_{F}$ keeps going up due to the increasing concentration gradient (green line) as shown in Fig. (4). Since the permeate pressure $\left(\mathrm{P}_{\mathrm{P}}\right)$ and the permeate osmotic pressure $\left(\Pi_{\mathrm{P}}\right)$ are usually very low compared to $\mathrm{P}_{\mathrm{F}}$ and $\Pi_{\mathrm{F}}$, respectively. If $\mathrm{P}_{\mathrm{P}}$ and $\Pi_{P}$ are neglected, the driving force in equation (6) can be simplified as the following:

$\Delta P_{\text {driving }} \approx P_{F}-\Pi_{F}$

Obviously, $\Pi_{F}$ can have a sharp increase and exceed $P_{F}$ during the HS solution injection period when the DO-HS technology is applied in the RO process. Therefore, a great negative driving force directed from the permeate to the feed side is gained and a fast back flow of the permeate through the membranes to the feed side happens where the HS solution contacts the membrane, resulting in a wave of process changes from RO to DO along the RO membranes. The osmosis pressure $\Pi_{F}$ of the HS solution decreases on its way, however it remains strong enough to create permeate back flow until it reaches the end of the pressure vessel.

Sagiv and Semiat [25] studied the effect of feed operating pressure on the DO backwash while the feed concentration was kept at $2 \% \mathrm{NaCl}$ with osmotic pressure of 13.7 bar.

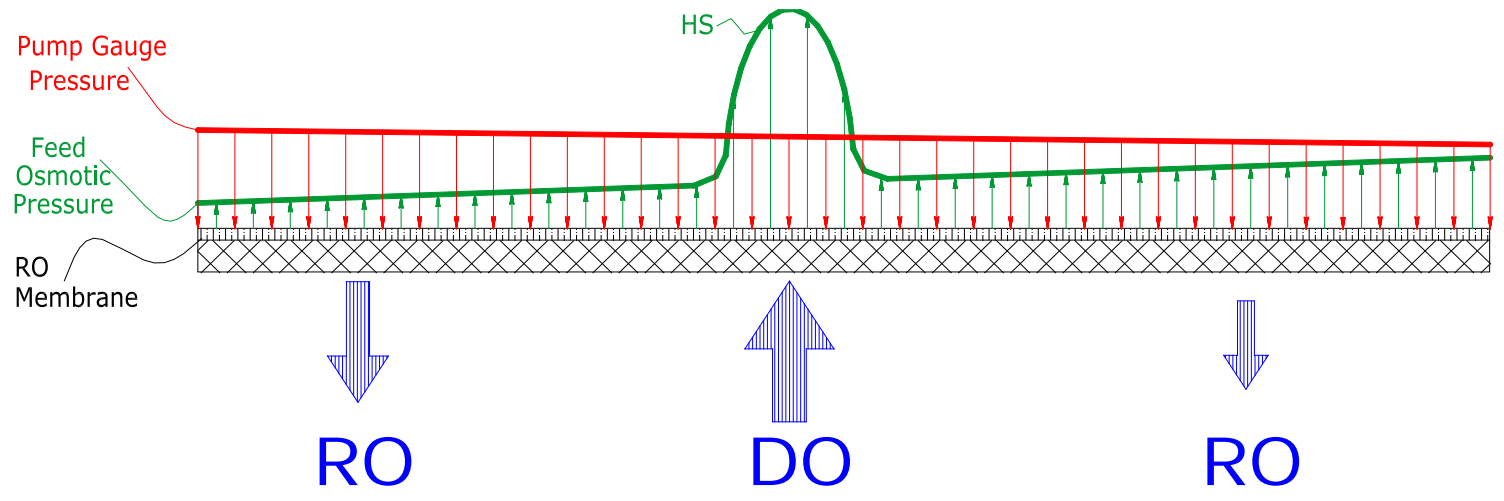

Fig. (4). Schematic of RO and DO with the injection of a HS solution. 
They found that the DO backwash flow rate decreased tremendously due to reduction of the driving force with an increase in the operating pressure from 0 to $10 \mathrm{bar}$.

\section{Effect of Backwash Time}

DO backwash experiments with a spiral wound RO membrane temporally fouled by $\mathrm{CaCO} 3$ precipitants was conducted and an analytical model to describe the DO backwash mechanism was developed by Sagiv and Semiat [25]. It was found that there were two distinct stages for the permeate back flow rate vs. time as shown in Fig. (5). The backwash flow rate was the highest at the beginning and sharply declined with time during Stage I and then slow down until leveled off during Stage II. This can be explained as follows. The initial osmotic pressure at the feed side for the DO backwash was the highest due to $\mathrm{CP}\left(\mathrm{K}_{\mathrm{CP}}>1\right)$ as shown in Fig. (5) since their DO backwash experiments were conducted as soon as the previous steady-state RO process stopped. With the course of DO backwash in Stage I, the CP layer is diluted rapidly due to the permeate dilution, which causes a quick decline in the driving force for the DO backwash until $\mathrm{C}_{\mathrm{w}}=$ $\mathrm{C}_{\mathrm{F}}$. Whereas, in Stage II, $\mathrm{C}_{\mathrm{w}}$ is less than $\mathrm{C}_{\mathrm{F}}$ due to the bulk dilution $\left(\mathrm{K}_{\mathrm{CP}}<1\right)$ and slowly decrease, causing a slow decline of a small driving force for the DO backwash until leveling off. The analytical model they developed is in agreement with their experimental results of Stage II without feed flow during the DO backwash. The results in Fig. (5) also suggest that the DO backwash period should be controlled within Stage I, maybe less than 20s. They reported that flux of the RO membrane newly fouled by $\mathrm{CaCO} 3$ could be resumed to its original level after the DO backwash with $0.5 \% \mathrm{NaCl}$ solution over $20 \mathrm{~s}$ [25].

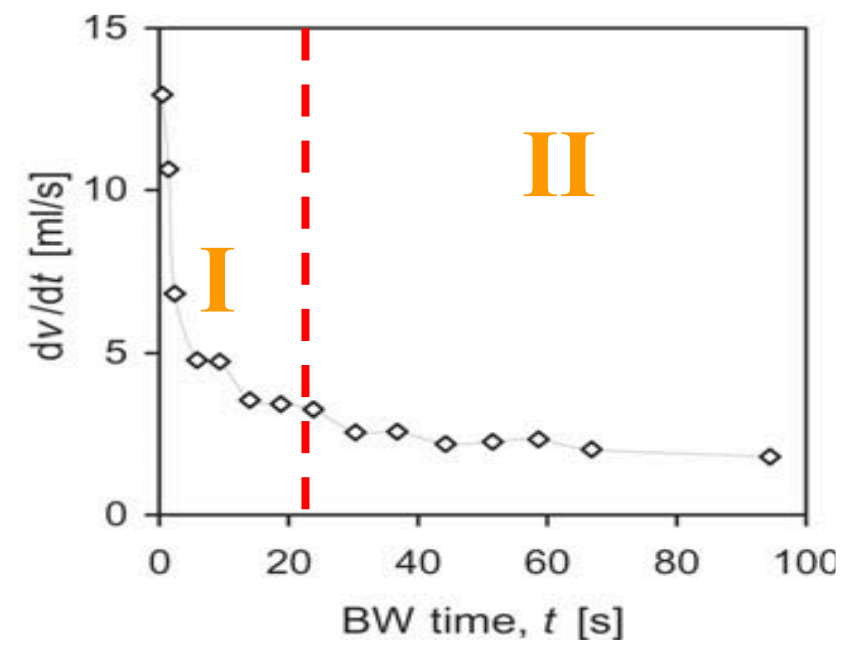

Fig. (5). Permeate back flow rate vs. time [25].

\section{Effect of Feed Concentration}

In the extreme case when the feed pressure is zero during the DO backwash, equation (8) can be simplified as follows:

$\Delta P_{\text {driving }}=-\Pi_{\mathrm{F}}$

Combination of equations (1) and (9), it is understood that a higher feed concentration will induce a larger driving force during DO backwash and then a higher DO backwash flow rate.
Sagiv and Semiat [25] investigated the effect of feed concentration in the range of $0.52 \%$ to $3.11 \% \mathrm{NaCl}$ on the DO backwash flow rate. Their results indicated that the feed concentration or feed osmotic pressure indeed performed an obvious effect on the DO backwash process as expected. However, Avraham et a l. [26] reported different observations. After short time of backwash (maybe less than 20s), the backwash flow rate decreased with an increase in feed concentration (the green arrow) when the feed concentration exceeded a certain value (which could be between $2.76 \%$ and $5.03 \% \mathrm{NaCl}$ here), although it followed the expectation (the red arrow) when the feed concentration was below the certain value. The former was explained by the internal $\mathrm{CP}$ effect at the permeate side during the backwash process as described in Fig. (5), which caused $C_{i w}$ much higher than $C_{P}$ and a decreasing $\mathrm{K}_{\mathrm{CP}}$ after a short time of backwash. In other words, the initial feed concentration has a self-limiting effect on backwash flux after backwash time of around 20s.

In a seawater RO desalination process, Liberman [21] reported that a super-saline solution made of $17 \% \mathrm{NaCl}$ with osmotic pressure of 170 bar could be injected into the feed stream over a few seconds in order to create a very strong net driving force of 55 bar for the DO backwash process. It was further suggested that concentration of HS solution injected into the feed stream during DO-HS cleaning process could be up to $25 \% \mathrm{NaCl}$ solution with osmotic pressure of $194 \mathrm{bar}$ [22]. However, flow rate, concentration and duration of the HS solution injection have to be well calculated in compliance with feed water chemistry, configuration of the RO train and pumps'curves, depending of the applications.

Very recently, a research aimed at further developing the innovative DO-HS backwash cleaning technique for RO fouling control in reclamation of municipal waste water has been commenced [40]. In Phase 1 of the study, selection of a DO-HS solution based on Sagiv \& Semiat's conclusion that the DO backwash could be effective in the initial 20s [25] has been conducted [41]. The study focused on the early $20 \mathrm{~s}$ period of DO backwash to establish the relationship between the backwash membrane flux and initial driving forceosmotic pressure so that a DO-HS solution could be preselected under the desired operating conditions. The membrane fluxes with different initial feed concentrations were calculated based on the backwash flow rate $\mathrm{dV} / \mathrm{dt}$ at $20 \mathrm{~s}$ measured by Sagiv \& Semiat [25]. Then osmolality of the corresponding $\mathrm{NaCl}$ solution was measured using an osmometer and was converted to osmotic pressure (I) with the known density [41].

Fig. (6) shows the backwash membrane flux as a function of the initial driving force at the backwash time of $20 \mathrm{~s}$. The flux increases with initial driving force (initial osmotic pressure) in the range of 5.17 to $31.1 \mathrm{~kg} / \mathrm{m}^{3} \mathrm{NaCl}$ solutions while the increasing trend slows down when the concentration exceeds $18.4 \mathrm{~kg} / \mathrm{m}^{3}$, which could be due to the effect of internal concentration polarization [25]. It should be pointed out that the relationship in Fig. (6) was established under the conditions of no applied pressures across the RO membrane and the net driving force was contributed from the feed $\mathrm{NaCl}$ solution as expressed by equation (9). From this relationship, the DO-HS solution may be selected. For instance, if the backwash membrane flux is expected to be $20 \mathrm{gfd}$ which is double of the typical membrane flux in this application, the 
net driving force needs 15 atm as indicated in Fig. (6). Then, osmotic pressure of the feed $\mathrm{NaCl}$ solution should be at least $15+5=20 \mathrm{~atm}$ if the actual operating pressure of $5 \mathrm{~atm}$ at the RO plant is taken into account and equation (8) should be applied. Therefore, the $\mathrm{NaCl}$ concentration can be estimated as $0.4 \mathrm{~mol} / \mathrm{L}$ or $23.4 \mathrm{~kg} / \mathrm{m}^{3}$. In order to obtain higher backwash flux, the RO brine from a seawater reverse osmosis (SWRO) plant can be selected as the HS solution, which contains total dissolved solid (TDS) of about $6 \%$ with osmotic pressure over $50 \mathrm{~atm}$. It is also an economic choice for implementation. The concentration, injection duration and flow rate of the HS solution, feed flow rate are expected to be optimized in future of the study.

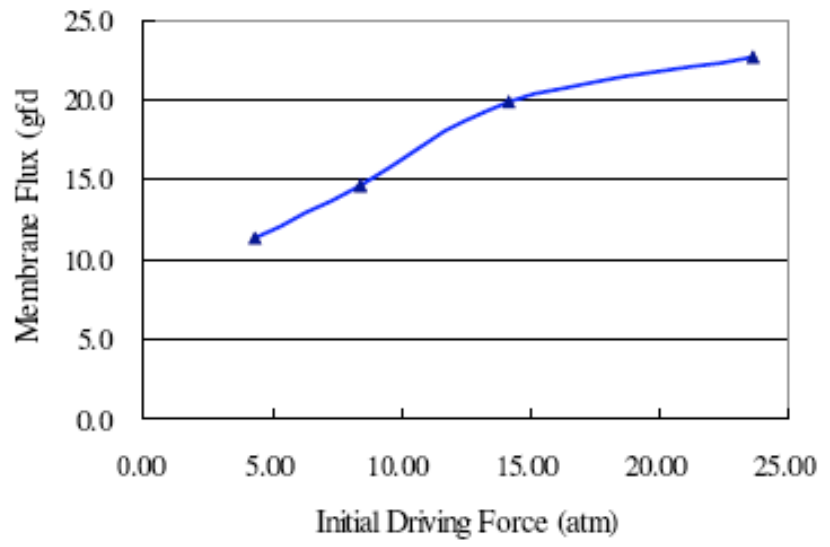

Fig. (6). Membrane flux vs. initial osmotic pressure at backwash time of 20 s.

\section{Effect of Permeate Pressure}

Rychen et al. [24] reported a new DO backwash process and device for producing pure water with RO and no pressure was supplied at the permeate side. Semiat's group [2527] also conducted fundamental research on the DO backwash cleaning without permeate pressure. It should be pointed out that the RO permeate for DO backwash was supplied from a permeate storage tank and the permeate back flow was driven by the gravity at the permeate side $[25,26]$ or a very low pressure pump [27] in their experiments.

However, as per equation (6), the driving force for DO backwash increases with an increase in the permeate pressure. Ando et a $l$. [16, 17] invented running method and treatment system for spiral wound membrane element and spiral wound membrane module and employed a permeate back pressure in the range of $0.05 \mathrm{MPa}$ to $0.3 \mathrm{MPa}$ for backwash of a spiral wound RO membrane module.

Liberman [20] pointed out that a typical spiral wound RO membrane module would be a tight multi-layered structure with high resistance for water passage and a very fast backsuction of water ("catastrophic" filtration) from the permeate side to the feed side would take place at the area close to the channel supplying the permeate water during the DO backwash. As a result, the permeate water may not reach the remote parts of the RO membranes before being entirely sucked to the feed side of the membranes through the parts adjacent to the permeate channel and the DO cleaning process would stop in a few seconds so that the membranes could not be cleaned uniformly. Therefore, he suggested to increase the gauge pressure at the permeate side of the membrane to a level slightly below the feed pressure of the raw saline solution, which is done by back pumping the permeate for a few seconds. The permeate back pressure may be at least 4 bar to make sure the DO backwash cleaning is efficient. However, in order to implement this method, the usual low pressure (low cost) equipment at the permeate side has to be replaced by a high pressure system such as high pressure pump, expensive stainless steel pipes, ports, valves etc, which may increase the cost significantly. It was further suggested that a super-saline solution made of $17 \% \mathrm{NaCl}$ with osmotic pressure of 170 bar could be injected into the feed stream over a few seconds in order to create a very strong net driving force of 55 bar for the DO backwash process in a seawater RO desalination process while the permeate pressure remained unchanged when the process transfers from RO to DO and back to RO as shown in Fig. (4) [22].

\section{CLEANING EFFICIENCY OF DO-HS METHOD}

The DO-HS method with a few seconds of HS solution injection can induce multiple cleaning mechanisms which consist of fouling lifting and sweeping, bio-osmotic shock and salt dissolve shock, thus can provide high cleaning efficiency [22].

\section{Lifting and Weeping of Foulants}

Fig. (7) shows a schematic of lifting \& sweeping of foulants during DO-HS cleaning [22]. After HS solution is injected over a few seconds into the feed water, the HS solution enters the feed channel like a wave which occupies one or two membrane elements and moves towards the brine

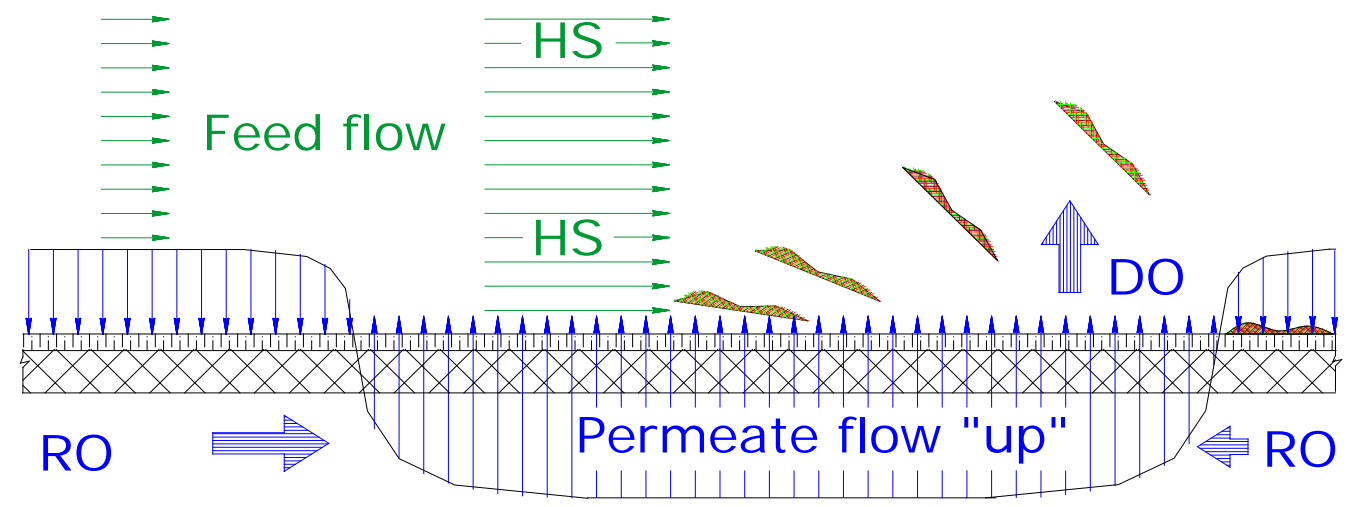

Fig. (7). Schematic of foulants lifting \& sweeping during DO-HS cleaning. 
outlet. In those places where HS solution contacts the membrane, the permeate changes its flow direction and backflows from the permeate channel to the feed channel. As a result, the fouling and/or scaling components are lift up vertically from the membrane surface, which is similar to the backwash operation in hollow fiber UF modules where the backflow of permeate is driven by hydraulic pressure. Meanwhile, velocity of the HS solution in the feed channel grows on its way to the brine due to the permeate "up" suction, which induces an additional horizontal force to flush the feed channel. Combination of the lifting up with the increased velocity of HS solution provides both stripping and sweeping effects to effectively clean the membrane surface and remove the foulants from the feed spacer.

\section{Bio-Osmotic Shock}

A sudden increase in the solute concentration around a cell can induce water drawn out of the cells through osmosis, causing the cell membrane shrink and detach from the cell wall. This also inhibits the transport of substrates and cofactors into the cell, thus fatal for bacteria, algae and fungi. For instance, even a normal saline with $0.9 \% \mathrm{NaCl}$ can effectively inhibit microbes. Therefore, the short injection of HS solution into feed stream can also effectively control biofouling of the RO membranes.

\section{Salt Dissolving Shock}

Since HS solution utilized in the DO backwash cleaning has high ionic strength, it would result in a low activity coefficient for each species in the solution. For a given temperature, each salt has its dissolving equilibrium constant in water, which equals the product of each species activity [42]. For example, the equilibrium constant of $\mathrm{CaSO}_{4}$ can be expressed as $\mathrm{K}_{\mathrm{S}}=\gamma_{\mathrm{Ca}} \cdot\left[\mathrm{Ca}^{2+}\right] \cdot \gamma_{\mathrm{SO} 4} \cdot\left[\mathrm{SO}_{4}{ }^{2-}\right]$. If the ionic strength of the solution is high, with decreasing $\gamma_{\mathrm{Ca}}$ and $\gamma_{\mathrm{SO}}$, concentration of the dissolved $\mathrm{Ca}^{2+}$ and $\mathrm{SO}_{4}{ }^{2-}$ can be increased to reach Ks. Hence the HS solution is capable of dissolving microcrystals growth on the RO membranes to prevent scaling. It should be pointed out that the scaling can be prevented if the DO-HS method is regularly applied from the start-up of the plant operation, however, dissolving of the scalant may be impossible once time for formation of the scaling goes on.

\section{Comparison of DO-HS with Conventional CIP}

Liberman et al. has compared the DO-HS cleaning with conventional CIP method [22]. As shown in Fig. (8), Scenario A describes $\mathrm{RO}$ permeate production as a function of time within one year under the conventional CIP cleaning, while Scenario B under DO-HS cleaning. In Scenario A, permeate production is gradually declined during the operation (including both restorable and non-restorable decline). This would cause increases in power consumption, pressure drop, product conductivity and membrane replacement rate, so it needs several CIP cleanings per year with high expenses. However, in Scenario B with the new method, with one or several automatic DO-HS cleanings a day, only very slight non-restorable decline occurs, but without restorable decline. From the comparison, it may be concluded that DOHS cleaning technology is very effective to keep the membrane continuously clean and ensure stable permeate production.

\section{IMPLEMENTATION AND APPLICATION OF DO-HS METHOD}

\section{Implementation of DO-HS}

Only simple mechanical changes are required for implementation of the DO-HS method into a current RO system as shown in Fig. (9) [43]. The blue line and green line represent the RO operating system and the current CIP cleaning system, respectively, whereas, the orange line represents the new DO-HS cleaning system. The HS solution supply tank and pipe need to add and connect to suction side of the high pressure pump. An evaporation system needs to add to the CIP cleaning system if reuse of the HS solution is required [43].

\section{Applications of DO-HS}

This new DO-HS cleaning technology has been applied in four brackish water RO trains at Dshanim Factory in Israel [22]. The raw feed comes from heavy fouled shallow wells
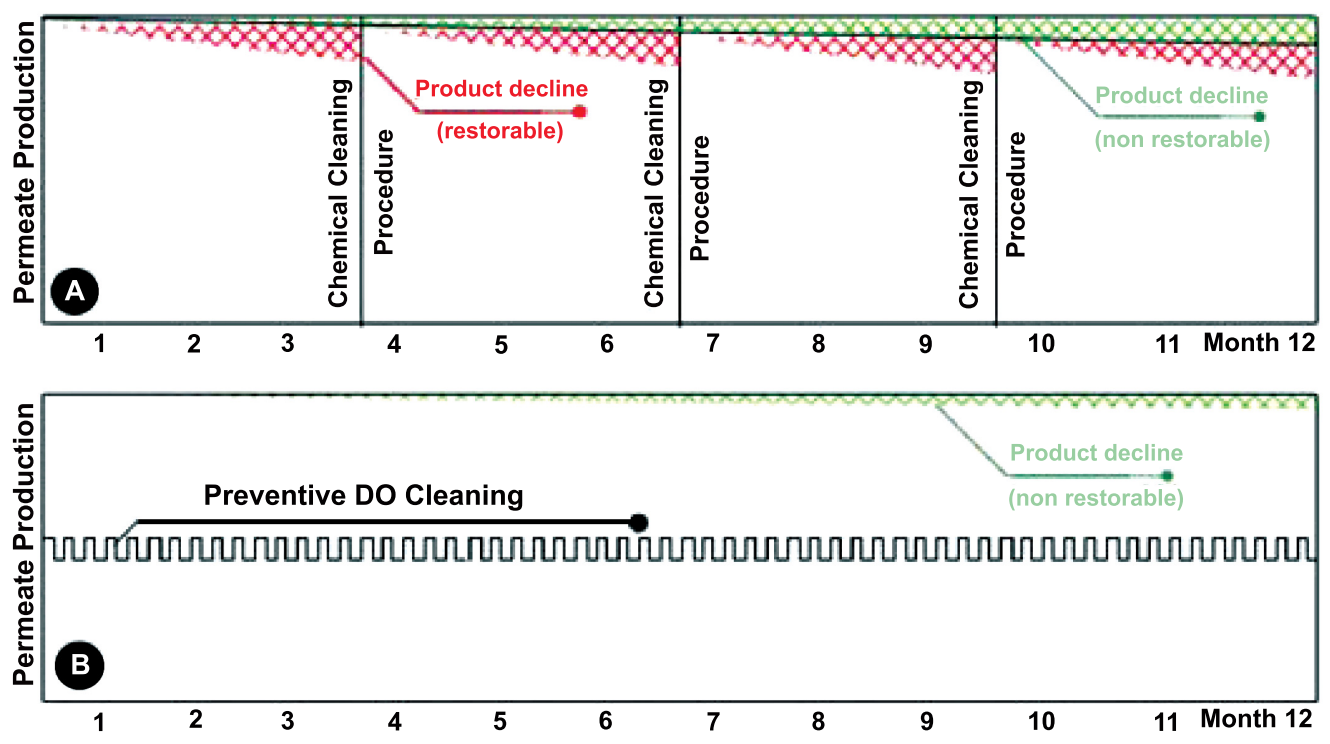

Fig. (8). Comparison of CIP and DO-HS cleaning. 


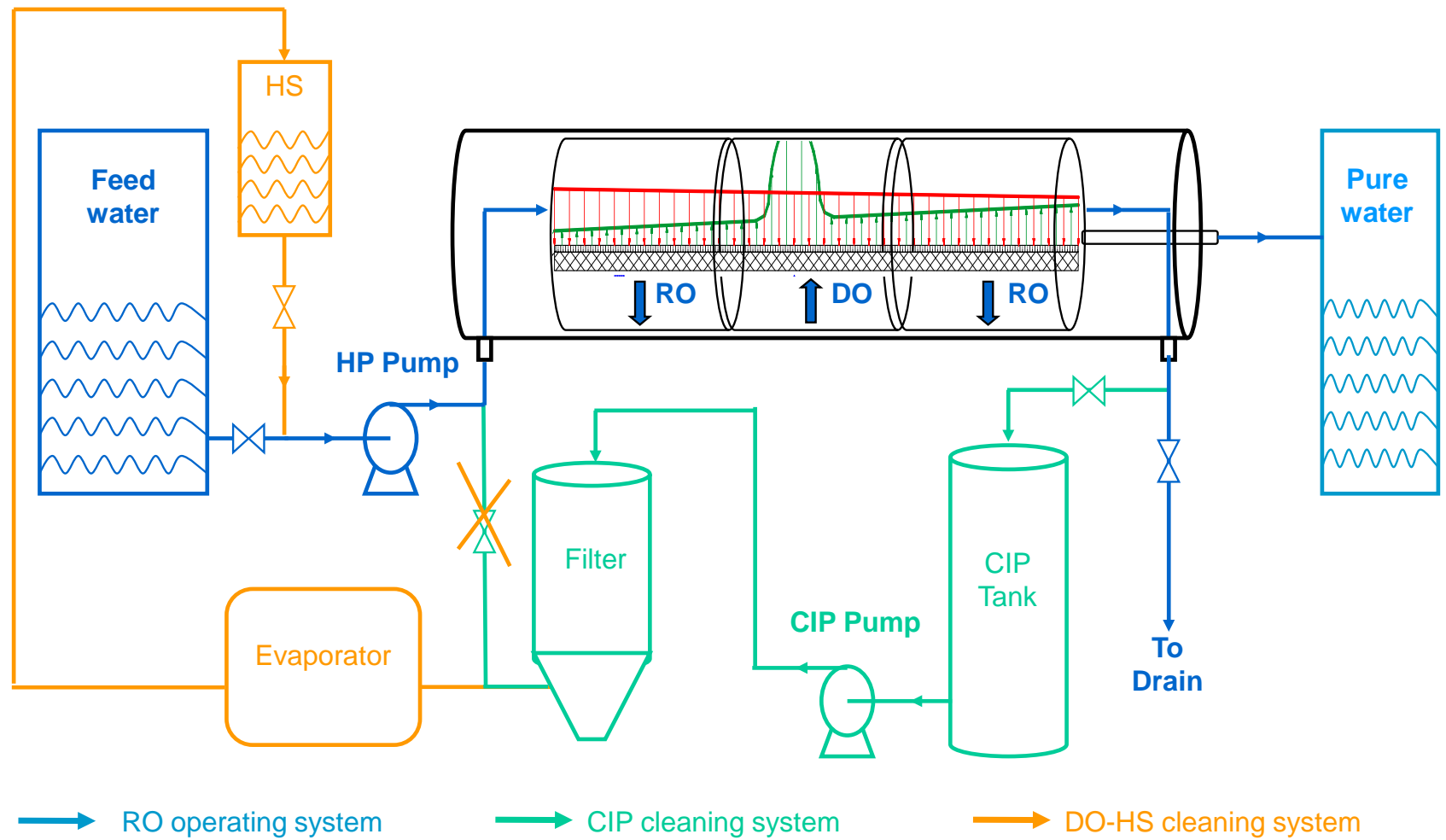

Fig. (9). Implementation scheme of DO-HS cleaning.

including $0.06 \mathrm{mg} / \mathrm{L}$ oil. Pretreatment involves a 5 micron cartridge filter only. Before implementation of DO-HS treatment, the plant was cleaned by conventional CIP procedure every week. However, after 50 days of DO-HS cleaning during which injection was made once a day except for the holidays, the results showed excellent performance in cleaning of the old and silica scaled RO membranes. Sixteen membranes had been weighed before and after DO-HS cleaning. Their weight reduced from $20-23 \mathrm{~kg}$ before cleaning to about $17 \mathrm{~kg}$ after cleaning, with $4-5 \mathrm{~kg}$ of fouling debris removed from each membrane. Therefore, with clean membranes, significant decrease in the pressure drop between feed and brine stream and also decrease in product conductivity were observed in each RO train [43], as shown in Table $\mathbf{1}$.

The DO-HS technology has been also successfully tested by some leading RO membrane manufactures such as DOW, Hydranautics and Toray. All of these results confirmed its feasibility, revealed no adverse effects on membrane performance, and approved it for implementation [43].

\section{CONCLUSION REMARKS}

DO-HS cleaning technology offers a novel environmental friendly on-line way to control fouling. It can operate without stopping high pressure pump and interruption of the RO process, avoid problems of aggressive chemical usage and disposal, but provide strong and intensive cleaning effects. With only simple system modification by using high salinity solution, it can save cost but meanwhile keep the membrane continuously clean and ensure stable and high quality permeate. Thus it succeeds in solving most potential problems existing in the previous physical and chemical cleaning strategies.

However, concentration, duration and flow rate of HS solution injection are the key parameters in this method and

Table 1. Comparison of Pressure Drop and Product Conductivity Drop During DO-HS

\begin{tabular}{|l|l|l|l|l|}
\hline RO trains & RO-1 & RO-2 & RO-3 & RO-4 \\
\hline \hline Before DO-HS cleaning (bar) & 5.60 & 6.00 & 5.40 & 5.50 \\
\hline After DO-HS cleaning (bar) & 4.40 & 4.10 & 3.20 & 4.00 \\
\hline Decrease in pressure drop & $21 \%$ & $32 \%$ & $41 \%$ & $27 \%$ \\
\hline Before DO-HS cleaning $(\mu \mathrm{S} / \mathrm{cm})$ & 42 & 87 & 76 & 60 \\
\hline After DO-HS cleaning $(\mu \mathrm{S} / \mathrm{cm})$ & 33 & $13 \%$ & $12 \%$ & 76 \\
\hline Decrease in product conductivity & $21 \%$ & $5 \%$ & \\
\hline
\end{tabular}


have to be well calculated in compliance with feed water chemistry, configuration of the existing RO train and pumps' curves, depending on the applications. Since DO-HS is a highly powerful instrument that can supply more than 100 bar of the cleaning force, improper implementation of this technique can damage the membrane element. To date, few studies have been conducted in this new method. Investigations on RO in reclamation of municipal wastewater have not been reported. Therefore, it is necessary to systematically investigate its major parameters and operation, and try to obtain the optimizing conditions for practical implementation. In addition, cost effectiveness of the method should be evaluated. For a proper choice of some major parameters, it is recommended that the concentration of HS solution injection is $5-10 \% \mathrm{NaCl}$ and the flow rate of $\mathrm{HS}$ solution is close to the normal $\mathrm{RO}$ operation as a starting point.

\section{ACKNOWLEDGEMENTS}

The authors acknowledge the support of National Research Foundation (Environmental \& Water Technologies) of Singapore under Incentive for Research \& Innovation Scheme (Project No.: 0601-IRIS-002-01). The authors would like to thank R. Gao for her contribution in the study to fulfill the requirements for her thesis.

\section{REFERENCES}

[1] Engineering Village. "RO fouling and RO fouling control", http://www.engineeringvillage2.org. 22 January, 2008.

[2] C.Y. Tang \& J.O. Leckie, "Membrane independent limiting flux for RO and NF membranes fouled by humic acid", Environ. Sci. Technol., vol. 41, pp. 4767-4773, 2007.

[3] S. Lee \& C.H. Lee, "Scale formation in NF/RO: Mechanism and control”, Water Sci. Technol., vol. 51, pp. 267-275, 2005.

[4] P. Bacchin, P. Aimar \& R.W. Field, "Critical and sustainable fluxes: Theory, experiments and applications", J. Membr. Sci., vol. 281, pp. 42-69, 2006.

[5] S.W. Myung, I. H. Choi, S. H. Lee, I. C. Kim and K. H. Lee, "Use of fouling resistant nanofiltration and reverse osmosis membranes for dyeing wastewater effluent treatment", Water Sci. Technol., vol. 51, pp. 159-164, 2005.

[6] C.Y. Tang, Y. N. Kwon \& J.O. Leckie, "Fouling of reverse osmosis and nanofiltration membranes by humic acid--Effects of solution composition and hydrodynamic conditions", J. Membr. Sci., vol. 290, pp. 86-94, 2007.

[7] A. Amoudi \& R.W. Lovitt, "Fouling strategies and the cleaning system of NF membranes and factors affecting cleaning efficiency", J. Membr. Sci., vol. 303, pp. 4-28, 2007.

[8] S. Hong \& M. Elimelech, "Chemical and physical aspects of natural organic matter (NOM) fouling of nanofiltration membranes", $J$. Membr. Sci., vol. 132, pp. 159-181, 1997.

[9] G. Ducom \& C. Cabassud, "Possible effects of air sparging for nanofiltration of salted solutions", Desalination, vol. 156, pp. 267274, 2003.

[10] J.Q.J.C. Verberk \& J.C. Dijk, “Air sparging in capillary nanofiltration”, J. Membr. Sci., vol. 284, pp. 339-351, 2006.

[11] E.R. Cornelissen, J.S. Vrouwenvelder, S.G.J. Heijman, X.D. Viallefont, D. Van der Kooij and L.P. Wessels, "Periodical air/water cleaning for control of biofouling in spiral wound membrane elements", J. Membr. Sci., vol. 287, 94-101, 2006.

[12] J.P. Chen, S.L. Kim \& Y.P. Ting, "Optimization of membrane physical and chemical cleaning by a statistically designed approach”, J. Membr. Sci., vol. 219, pp. 27-45, 2003.

[13] W.S. Ang, S. Lee \& M. Elimelech, "Chemical and physical aspects of cleaning of organic-fouled reverse osmosis membranes", $J$. Membr. Sci., vol. 272, pp.198-210, 2006.

[14] G. Pearce, "Introduction to membranes: Fouling control", Filt. Sep., vol. 44, pp. 30, 2007.
[15] K. S. Spiegler and J. H. Macleish, "Molecular (osmotic and electroosmotic) backwash of cellulose acetate hyperfiltration membranes", J. Membr. Sci., vol. 8, pp. 173-192, 1981.

[16] M. Ando, K. Ishii, S. Ishihara, "Running method and treatment system for spiral wound membrane element and spiral wound membrane module", EP 1170053 A1 20020109, 2002.

[17] M. Ando, T. Watanabe, H. Yoshikawa, "Treatment system having spiral membrane element and method for operating the treatment system", EP 1323461 A2 20030703, 2003.

[18] B. Liberman, "Direct osmosis cleaning", PCT/IL/2003/000984, 2004.

[19] B. Liberman, "Methods of direct osmosis membrane cleaning online for high SDI feed after pretreatment", IDA Workshop, TempaSan Diego, 22-26 March, 2004.

[20] B. Liberman, "Direct Osmosis Cleaning", Patent a pplication, WO2004/062774, 2004 and US Patent Application: 20070246425, 2007.

[21] I. Liberman, "RO membrane cleaning method", PCT WO 2005/123232 A2, 2005.

[22] B. Liberman, \& I. Liberman, "RO Membrane Cleaning - Replacing membrane CIP by Direct Osmosis Cleaning", Desalination \& $\mathrm{Wa}$ ter Reuse, vol. 15, pp. 28-32, 2005.

[23] I. Liberman, "RO membrane cleaning method", United States Patent Application, 20070181497, 2007.

[24] P. Rychen, S. Alonso, T. Meier, "Process and device for producing pure water", EP19960810678, 1996.

[25] A. Sagiv, R. Semiat, "Backwash of RO spiral wound membranes", Desalination, vol. 179, pp.1-9, 2005.

[26] N. Avraham, C. Dosoretz \& R. Semiat, "Osmotic backwash process in RO membranes", Desalination, vol. 199, pp. 387-389, 2006.

[27] A. Sagiv, N.Avraham, C. G. Dosoretz, R. Semiat, "Osmotic backwash mechanism of reverse osmosis membranes", J. Membr. Sci, vol. 322, pp. 225-233, 2008.

[28] R. W. Holloway, A. E. Childress, K. E. Dennett, T. Y. Cath, "Forward osmosis for concentration of anaerobic digester Centrate", Water Res., vol. 41, pp. 4 005-4014, 2007.

[29] W. Tang, H. Y. Ng, "Concentration of brine by forward osmosis: Performance and influence of membrane structure", Desalination, vol. 224, pp. 143-153, 2008.

[30] E.R. Cornelissen, D. Harmsen, K.F. de Korte, C.J. Ruiken, J. J. Qin, H. Oo and L.P. Wessels, "Membrane fouling and process performance of forward osmosis membranes on activated sludge", $J$ Membr. Sci., vol. 319, pp. 158-168, 2008.

[31] K.A. Kekre, J. J. Qin, M. H. Oo, G. Tao, C.L. Lay, C. H. Lew, E.R. Cornelissen, L.P. Wessels, C.J. Ruiken, K.F. de Korte, "Osmotic membrane bioreactor: Preliminary pilot study on effects of osmotic pressure on membrane flux and air scouring on fouling", in Proc. of IWA Regional Conference, 2-4 June, Moscow, Russia, 2008.

[32] A. Achilli, T.Y. Cath, E.A. Marchand, A.E. Childress, "The Novel Osmotic Membrane Bioreactor for Wastewater Treatment", In Proc. of the 81st Annual Water Environment Federation Technical Exhibition and Conference, October 18-22, Chicago, USA, 2008.

[33] R.E. Kravath, J.A. Davis, "Desalination of seawater by direct osmosis", Desalination, vol. 16, pp. 151-155, 1975.

[34] J.R. McCutcheon, R.L. McGinnis, M. Elimelech, "A novel ammonia-carbon dioxide forward (direct) osmosis desalination process", Desalination, vol. 174, pp. 1-11, 2005.

[35] S. E. Skilhagen, J. E. Dugstad and R. J. Aaberg, "Osmotic powerpower production based on the osmotic pressure difference between waters with varying salt gradients", Desalination, vol. 220, pp. 476-482, 2008.

[36] S. Loeb and R. S. Norman, "Osmotic power plants", Science, vol. 189, pp. 654-655, 1975.

[37] B. Jiao, A. Cassano, E. Drioli, "Recent advances on membrane processes for the concentration of fruit juices: a review", J. Food Eng., vol. 63, pp. 303-324, 2004.

[38] J. C. Wright, R. M. Johnson, S. I. Yum, "DUROS® osmotic pharmaceutical systems for parenteral \& site-directed therapy", Drug Deliv. Technol., vol. 3, pp. 64-73, 2003.

[39] T.Y. Cath, A. E. Childress and M. Elimelech, "Forward osmosis: Principles, applications, and recent developments", J. Membr. Sci., vol. 281, pp. 70-87, 2006. 
[40] http://app.mewr.gov.sg/data/ImgCont/434/CDS5296_Awarded ProjectsforEWRP200601RFP.pdf, 18 Dec 2008.

[41] R. Gao, "UF-RO pilot study at Changi Water Reclamation Plant", Master Thesis Chapter 5, Nanyang Technological University, Singapore, 2008.
[42] K. W. Chau, "Investigation on effects of aggregate structure in water and wastewater treatment," Water Sci. Technol., vol. 50, pp. 119-124, 2004.

[43] Membrane Recovery Ltd, http://www.membrane-recovery.com/, 18 Dec 2008.

Received: December 22, 2008

(C) Qin et al.; Licensee Bentham Open.

This is an open access article licensed under the terms of the Creative Commons Attribution Non-Commercial License (http://creativecommons.org/licenses/by-nc/3.0/) which permits unrestricted, non-commercial use, distribution and reproduction in any medium, provided the work is properly cited. 